\title{
Creating and implementing a biodiversity recording app for teaching and research in environmental studies
}

Article

Published Version

Open Access

White, E., Basford, L., Birch, S., Black, A., Culham, A., McGoff, H., Lundqvist, K., Oppenheimer, P., Tanner, J., Wells, M. and Mauchline, A. (2015) Creating and implementing a biodiversity recording app for teaching and research in environmental studies. The Journal of Educational Innovation, Partnership and Change, 1 (1). ISSN 2055-4990 Available at https://centaur.reading.ac.uk/39679/

It is advisable to refer to the publisher's version if you intend to cite from the work. See Guidance on citing.

Published version at: https://journals.gre.ac.uk/index.php/studentchangeagents/article/view/166

Publisher: JISC

Publisher statement: Open Access Policy This journal provides immediate open access to its content on the principle that making research freely available to the public supports a greater global exchange of knowledge.

All outputs in CentAUR are protected by Intellectual Property Rights law, including copyright law. Copyright and IPR is retained by the creators or other copyright holders. Terms and conditions for use of this material are defined in the End User Agreement. 


\section{www.reading.ac.uk/centaur}

\section{CentAUR}

Central Archive at the University of Reading

Reading's research outputs online 


\section{Creating and Implementing a Biodiversity Recording App for Teaching and Research in Environmental Studies}

Elizabeth White, Liam Basford, Stephen Birch, Alison Black, Alastair Culham, Hazel J. McGoff, Karsten O. Lundqvist, Philippa Oppenheimer, Jonathan Tanner, Mark Wells, Alice L. Mauchline

The University of Reading

\section{Background}

The ready availability of mobile devices and the trend in public desire to use mobile apps (Herrington and Herrington, 2007) provides the perfect opportunity to enable teaching to harness the benefits of mobile technology. With $80 \%$ of internet access expected to be through mobile devices by 2015 (Rossing et al, 2012), it is important that Higher Education should exploit this opportunity to enhance learning by proactively adapting teaching methodology to take full advantage of the changing consumption of technology.

The use of citizen science projects and the crowd sourcing of data from non-professional scientists has both benefits and limitations, but the approach is readily applicable to research initiatives at universities. The collection of large amounts of verifiable scientific data (such as that collected within recording apps) is more efficient than traditional data collection, with greater sample size compensating for reduced accuracy (Gardiner et al, 2012). The citizen science approach also fosters the partnership between staff and students, by creating a framework that allows easy contribution from many individuals and by producing a database that can be used to support further research projects.

\section{Aim}

The aim of this project was to develop a bespoke mobile recording app for collating records of biodiversity sightings on the Whiteknights campus at the University of Reading. This innovation was achieved through a multi-disciplinary partnership of staff and students.

\section{Organisational and historical context}

The campus for which the app was designed, Whiteknights, has held the Green Flag Award four years running and strives to provide a haven for wildlife and biodiversity (University of Reading, 2014). The Whiteknights Biodiversity Blog was established in 2011 as a central repository for campus biodiversity data

(http://blogs.reading.ac.uk/whiteknightsbiodiversity/). This hub of biodiversity online has generated increasing interest and coordinates multiple records, including an ever-growing phenological dataset.

Biodiversity on campus is taught in a range of modules across several Schools and is explored through a number of activities which engage both students and the general public. Voluntary work is often conducted by student societies, though identification events, open to both students and public, have more recently been taking place. Events such as the BioBlitz, a twenty-four-hour wildlife recording session, engage natural history groups in the area and promote campus biodiversity. With all these activities taking place, it was hoped that a 


\section{Case Studies}

mobile app might help streamline and standardise the way in which wildlife is recorded across campus.

\section{Specifications of the project}

For the reasons outlined above, a collaborative project between staff and students was undertaken at the University of Reading to create a mobile application for recording campus biodiversity, for both fieldwork research and individual enjoyment. The project received funding from the Teaching and Learning Development Fund at the University and aimed to meet three of the Fund's main priorities:

- To engage students in research and enquiry;

- By running the project alongside research staff, the students were to gain first-hand experience of organising and conducting research projects.

- Helping shape the final product provided a direct way for students to engage in both research and enquiry and to consolidate their learning by blogging about and disseminating the app and their experiences.

- To develop highly-employable graduates;

- Owing to the inter-disciplinary nature of the project, students gained many generic employability skills relating to communication and team-work.

- Subject-specific skills were also targeted, through species-identification training, and there were networking opportunities for potential placements and employment.

- Through the creation of the app, students from Computing and Typography were able to gain experience of designing a bespoke product, something particularly relevant to Typography.

- Handling such technology provided all students with skills relevant to today's employers.

- To evolve approaches to teaching and learning;

- As both students and staff were involved in the project, the final outcome was developed by the target audience and therefore will be of benefit to both user groups.

- Staff were able to utilise the student input, not only in the project, but also in other teaching, by taking note of the preferences of a subsample of students.

- Whilst the product is already valuable in evolving Reading's approach to teaching in Environmental Studies, Agriculture and Biological Sciences, the project may act as a model for developing other bespoke applications with the

\section{Pedagogic rationale}

It is hoped that the app itself will benefit lecturers by streamlining data collection during teaching and learning activities, whilst engaging students and highlighting the wealth of biodiversity available on campus. Previous studies show that the use of mobile apps improves engagement (Hargis et al, 2014), which is thought to result in better understanding, 


\section{Case Studies}

as demonstrated in other projects which combined the use of apps and teaching to produce consistently higher test scores (Herrington and Herrington, 2007).

The app may also be of benefit to the teaching of classes of large size, as the ability to streamline data collection allows for more time to be devoted to interacting with students and permits easier processing of large quantities of post-fieldwork data. The app also allows for active learning by a wider audience. Since active learning is thought to improve examination performance (Freeman et al., 2014), the ability to apply this approach to classes of large size may add further value.

By demonstrating the manifold benefits of using mobile applications to support teaching and learning, the Whiteknights biodiversity app project offers a blueprint for how other teams might implement app creation and use, therefore streamlining other projects to create a proliferation of highly-functional, bespoke apps.

\section{Implementation}

Team: A multi-disciplinary team of staff and students was assembled. Team members from Environmental Science, Biology and Agriculture were, as target users, responsible for the app content, whilst Typography \& Graphic Communication created the branding and improved usability and Systems Engineering coded the ideas. Although each discipline had roles within the project, ideas from every school were pooled to exploit the diversity of the group's expertise and knowledge in the creation of a more cohesive app. Similarly, having both staff and students working in partnership on the app allowed for the representation of the views and suggestions of all target users, which was important in the creation of an app which would be intuitive and therefore a pleasure to use.

Scoping study: Students from the schools representing target users met with staff to compile a bank of ideas which would make the app useful in various contexts around the university. This simultaneously raised awareness of the project, ensuring use of the app upon completion, especially as the fundamental design would be based on the requirements of these target users.

HackDay: The team held a 'HackDay' to discuss the way in which the app would be developed and how the project should progress. The ideas from the scoping study were then fed back to the group for development and to ascertain the logistics of achieving these goals. It was important that the team aimed for 'essential' targets that were achievable within the budget and time-frame of the project (Table 1). Also drawn up was a list of 'desirable' targets that could be worked on if time and budget allowed. 


\section{Case Studies}

Table 1. Requirements of the biodiversity recording app

\begin{tabular}{|l|l|l|l|}
\hline Time \& date & Required & $\begin{array}{l}\text { Automatically } \\
\text { captured }\end{array}$ & $\begin{array}{l}\text { Time and date } \\
\text { format }\end{array}$ \\
\hline GPS & Optional & $\begin{array}{l}\text { Data captured - } \\
\text { yes/no }\end{array}$ & Longitude \& latitude \\
\hline Photo & Optional & Link to camera & Image \\
\hline $\begin{array}{l}\text { Organism } \\
\text { group }\end{array}$ & Optional & Drop-down menu & 8 groups (see below) \\
\hline $\begin{array}{l}\text { Organism } \\
\text { name }\end{array}$ & Optional & $\begin{array}{l}\text { Two boxes } \\
\text { 1. Common name } \\
\text { 2. Species name }\end{array}$ & Predictive text \\
\hline User code & Optional & Could be student ID & Free text \\
\hline Project code & Optional & Unique code & Free text \\
\hline Confidence & Optional & Drop-down menu & 5 levels (see below) \\
\hline rating & Optional & Field notes & Free text \\
\hline Notes & Ond & &
\end{tabular}

App search: As opposed to creating an app from scratch (a very time-consuming exercise), a database of similar projects was compiled to allow exploration of a range of customisable software that could provide the required functionality. Through this process, EpiCollect was selected and the software designers were contacted to get access to the most up-to-date code. EpiCollect (www.epicollect.net), open-source software developed at Imperial College London, was found to have all the functionality required, as well as providing a web interface. EpiCollect was considered particularly suitable, as it works offline to record data, has inbuilt GPS location recording and has the ability to synchronise records over Wi-Fi to the project's own server.

Customisation \& branding: Typography and Graphic Communication brought individuality to the app and ensured that it had a definitive and distinctive logo, important both for marketing and distribution and to make clear to potential downloaders and users what the product was. Branding was also important in the creation of a supporting website, as it again allowed the page to be clearly identified despite other design constraints.

A web homepage, KiteSite (www.reading.ac.uk/herbarium/kitesite), allowed the app itself to stay uncluttered and offered information and user support to augment the app. Guides (such as how to download the app, ID resources, and application capabilities) helped to make the app as user-friendly as possible, whilst information about the capabilities and possible uses of KiteSite provided for subsequent application in classroom and fieldwork settings. The website also served as a hub for information about such things as later developments (aided by a Twitter feed for news and community discussion) and housed links to the data and maps, allowing access from any platform. 


\section{Case Studies}

As there are on the Reading campus growing numbers of reintroduced red kites, 'KiteSite' was the name chosen to represent the app; it conveyed also the concept of a bird's eye view of the map of biodiversity sites as created by the app. Such linkage between the Reading area, the bird, the campus and the app has helped to develop a sense of community in the app's use.

App content \& function: The main function of KiteSite is the recording of data from around the campus, either by individuals or as part of group work. By creating custom forms with the fields required for phenological data, users can tailor the forms to their specific individual needs. The inclusion of photos allows for further corroboration of records, whilst a confidence score permits records to be evaluated by other users for their validity. All these entries go to a database which can then be searched. Fields can be searched individually and a map is created within the EpiCollect site to show the data points spatially, enabling other users at a later date to find the location of recordings.

Testing \& Feedback: Once the first prototype was available, it was important to test out the app for problems. Testing was undertaken by the students involved in the project as well as by additional student volunteers, to ensure that the app was intuitive to new users and to help explain some features. This was done within a stereotypical class setting and in conjunction with staff to identify problems/issues for both groups of end-users. To mimic a typical class situation, the students received a short instructional species-identification practical before they walked independently to identify plants on the ground and to record them, using the app.

Feedback highlighted app-usage issues that could then be improved within the limits of the software programming, to the benefit of both students and staff. The app was then revised in line with these recommendations to create the final draft product to be released to a limited number of students for testing more widely. Any issues arising from this development stage were dealt with where possible to produce the finished product.

Dissemination and use: The app design process revealed many ways in which it could be implemented in teaching, making it useful to staff. The team held a launch to which all staff at The University of Reading were invited to allow them to discover such potential benefits the app could bring to their teaching as:

- teaching a large group; collection of data is less time-consuming than paper recording, therefore allowing more participants and larger classes.

- students can make more accurate records to be kept for later identification, thus making extra-curricular activities more accessible.

- removing the process of collating records to Excel, the time-saving elements of the app are considerable. Records are also provided in a quick and easily-consumable form. For example, GPS coordinates are easily exportable to GIS.

- supplementing the Whiteknights Biodiversity Blog, an already significant hub of biodiversity activity, allowing the continued build-up of records, particularly those for phenological use.

- allowing widespread dissemination of data by providing access from various platforms. This prevents limitations on the distribution of data and allows those with an interest to view findings without difficulty. 


\section{Case Studies}

The student newspaper was helpful when publicising the project and app to the student community; it published a front page article on the project, focusing on the staff-student partnership, and this proved to be a good platform to engage the wider student group, including student societies.

\section{Evaluation}

The partnership between staff and students has provided opportunities for both groups: students have been able to influence the way in which the advancement of teaching is conducted, whilst staff have seen the ways in which students would like to proceed with their education. Changing the way in which teaching is conducted to allow greater numbers to participate in active teaching is beneficial to a number of fields, not just within a biology initiative. The incorporation of different disciplines within this project only serves to emphasise that such an app is not limited to environmental purposes and that multidisciplinary teams are particularly beneficial in their own right.

The students involved in the project have enhanced their employment skills as per the TLDF's priorities, many of which refer to the beneficial nature of a multi-disciplinary team. The members of the student team wrote about their involvement in this project in a series of reflective blogs: (http://blogs.reading.ac.uk/whiteknightsbiodiversity/category/studentprojects/kitesite/).

Future users, however, may also benefit from using up-to-date and relevant technology which may be applicable in their subsequent careers. The sense of community and engagement created by contributing to a biodiversity database is also important. Giving students and local natural history groups an interest in the site will help preserve the campus as a biodiversity hub.

Whilst, as already mentioned, working in a multi-disciplinary team provided opportunities to develop transferable skills such as communication, it also provided an insight into the rationale and processes behind different subjects. Experience of this may help students to acclimatise to the complexities of later work environments. The collaboration between staff and students provided an insight into how both groups approach teaching and learning, enabling, firstly, the development of a well-designed app and, secondly, a sense of the ways by which teaching activities may be improved.

As to the benefits of the app in use, that it can streamline data collection and processing is a great advantage, especially in harnessing the large student body available to lecturers; the standardisation and the accessibility of the collected data also allow for participation outside the class environment, which may create a better sense of community between users. The benefits are transferable and not limited to the biological field in which the app was developed, allowing the KiteSite project to become a blueprint for other applications; the Reading experience suggests that the combination of app and website, the latter providing user guides, ID resources and user guides, will best exploit the app's potential.

At the time of writing, large-scale use of the app in teaching has yet to commence. KiteSite has, however, been used by the student ornithological society, which found the app useful when recording bird sightings; this may be attributable to the simplicity of the forms allowing for rapid data entry, maximising the time spent looking for birds. The emphasis upon 


\section{Case Studies}

functionality and intuitiveness in the app allowed for ease of use for first-time users, with minimal support needed - a consideration for other app development projects.

The app has been met with enthusiasm by staff, who are keen to see it applied practically. Their proposed ideas of ways to integrate it into the curriculum include: recording autumn tree phenology events; plant ID skills training; vegetation surveys and zoology ID training. Staff were keen to demonstrate KiteSite at Open Days as an innovative part of the suite of resources available to support student learning at the University. The student team has inspired all these examples of novel ideas for field teaching approaches through making this bespoke recording app available for their tutors to use. We are keen to promote creation of similar software in other universities, building on the groundwork we have laid out to create many more tailor-made apps. The efficient and innovative use of technology in teaching through a medium such as a bespoke app makes it appropriate for use in many faculties.

\section{Lessons learnt}

One of the many reasons why we are keen to promote the app is the versatility of the EpiCollect system. The availability of EpiCollect's highly-functional and customisable software significantly shortened the time-frame for our development project. With the formula used by our multi-disciplinary team, apps can be developed even faster, for we believe our approach functions well, perhaps because the many expert influences and ideas from each school have helped to create a very well-balanced app. However, given our experience, there are recommendations for future projects:

Firstly, there was some difficulty in customising the iOS version of the app. Therefore, in subsequent projects, we would ensure that the basic code was customisable for this platform.

Secondly, limitations were imposed by Google on the EpiCollect system, not allowing the data map to be embedded in forked versions (versions generated from the EpiCollect source by third-party developers). It is possible that other software exists with this functionality, as well as other requirements.

However, designing an app from scratch may be the only way fully to customise software. Allowing a larger time-frame and budget for this may be appropriate for larger-scale projects.

\section{Conclusions}

Overall, the project has been a success; the app is beneficial to teaching, whilst the experience gained by students on the project is invaluable. Harnessing technology to evolve teaching approaches is important to maintaining relevancy in modern education. Projects like KiteSite provide an easy window to exploit the combination of technology and teaching. With this success, we hope others will be enthused to create their own apps to enhance teaching in multiple fields.

\section{Acknowledgements}

The authors would like to thank the Teaching and Development Fund at the University of Reading for their financial support. Drs Becky Thomas and Jonathan Mitchley provided expert support throughout the project. 


\section{Case Studies}

\section{Reference list}

Freeman, S., Eddy, S.L., McDonough, M., Smith, M.K., Okoroafor, N., Jordt, H. and Wenderoth, M.P. (2014) 'Active learning increases student performance in science, engineering and mathematics.' Proceedings of the National Academy of Sciences of the United States of America, 111, 8410-8415.

Gardiner, M.M., Allee, L.L., Brown, P.M.J., Losey, J.E., Roy, H.E. and Smyth, R.R. (2012) 'Lessons from lady beetles: accuracy of monitoring data from US and UK citizen-science programs.' Frontiers in Ecology and the Environment, 10(9), 471-476.

Hargis, J., Cavanaugh, C., Kamali and T., Soto, M. (2014) 'A federal higher education iPad mobile learning initiative: Triangulation of data to determine early effectiveness.' Innovative Higher Education, 39(1), 45-57.

Herrington A. and Herrington J. (2007) 'Authentic mobile learning in higher education.' In: AARE. International Educational Research Conference, 28 November 2007. Fremantle, Western Australia: AARE.

Rossing, J.P., Miller, W.M., Cecil, A.K. and Stamper, S.E. (2012) 'iLearning: the future of higher education? Student perceptions on learning with mobile tablets.' Journal of the Scholarship of Teaching and Learning, 12(2), 1-26.

University of Reading (2014) 'The university and the environment.' Reading: University of Reading. Available from: http://www.reading.ac.uk/about/about-environment.aspx (Accessed: 19 August 2014). 